\title{
Environmental Values in Post-socialist Hungary: Is It Useful to Distinguish Egoistic, Altruistic and Biospheric Values?*
}

\author{
JUDITH. I. M. DE GROOT** \\ Bournemouth University \\ LINDA STEG and MARTIJN KEIZER \\ University of Groningen \\ ANDREA FARSANG and ALAN WATT \\ Central European University, Budapest
}

\begin{abstract}
In this article the authors examine whether the significance of biospheric values as a separate cluster next to egoistic and altruistic values is mainly a Western European phenomenon or whether biospheric values are also endorsed as a value in its own right in post-socialist Hungary. In two different samples $(N=856$ and $N=840)$, the multi-group method revealed that egoistic, altruistic and biospheric values can be distinguished empirically in Hungary. Their findings suggest that Hungarians not only care for nature and the environment as such, but that these values are translated into feelings of moral obligation to protect the environment: biospheric values strongly helped to explain personal norms towards various environmental behaviours. The authors' results suggest that bisopheric values are relevant for understanding environmental beliefs, norms and actions in Hungary.
\end{abstract}

Keywords: biospheric values, environmental values, pro-environmental behaviour, sociology and environment, Hungary

Sociologický časopis/Czech Sociological Review, 2012, Vol. 48, No. 3: 421-440

\section{Introduction}

Tackling environment problems is a key policy goal featuring on the international political agenda (Intergovernmental Panel on Climate Change [IPCC 2007]). It is widely acknowledged that environmental problems are rooted in human behaviour and that these problems can be reduced by changing such behaviours

* This research was supported by the EU-funded project BARENERGY (www.barenergy. eu). We would like to thank Stø Eivind, Shane Fudge, Birgitta Gatersleben, Stefani Heinzle, Sonja Luethi, Isabelle Moussaoui, Harald Throne-Holst and Rolf Wuestenhagen for their suggestions to further improve the questionnaire.

** Direct all correspondence to: Judith I. M. de Groot, School of Design, Engineering, Computing, Department of Psychology, Bournemouth University, Talbot Campus, Poole, BH12 5BB, United Kingdom, e-mail: jdgroot@bournemouth.ac.uk. 
[Nickerson 2003; Gardner and Stern 2002]. Environmental behaviour includes those behaviours that change the availability of materials or energy sources from the environment or alter the structure and dynamics of ecosystems or the biosphere [Stern 2000]. It comprises a variety of behaviours that either harm the environment (e.g. littering, car use, energy use, i.e. environmentally harmful behaviour) or benefit the environment (e.g. recycling, the adoption of sustainable energy sources, i.e. pro-environmental behaviour). Understanding factors underlying environmental behaviour is crucial in promoting pro-environmental behaviours in order to improve local and global environmental quality.

Values are often regarded when studying environmental behaviour [e.g. Dunlap, Grieneeks and Rokeach 1983; Naess 1989]. Values, such as respect, equality, and unity with nature, are desirable trans-situational goals that vary in importance and serve as guiding principles in the life of a person or other social entity [Schwartz 1992]. As such, values are general determinants of environmental behaviour that include some key features. First, values are abstract and transcend situations, suggesting that they may influence a wide range of behaviour-specific determinants and behaviours in a variety of contexts [Seligman and Katz 1996]. Second, the total number of values is relatively small compared to the countless behaviour-specific beliefs. Consequently, they provide an economically efficient instrument for describing and explaining similarities and differences between persons, groups, nations, and cultures [Rokeach 1973]. The causal influence of values on environmental behaviour has been documented by means of cross-lagged panel research [Thøgersen and Ölander 2002]. Hence, values are a relevant starting point for understanding and changing environmental behaviour. Through activating or strengthening certain values, it is possible to influence a range of environmental behaviours simultaneously [Thøgersen and Ölander 2006].

This article aims to examine which values are associated with a range of personal norms, that is, feelings of moral obligation to act pro-environmentally [Schwartz 1977]. More specifically, we study whether biospheric values can be distinguished as a separate value cluster from egoistic and altruistic values in post-socialist Hungary, or whether biospheric values are only endorsed in their own right in Western European countries [e.g. de Groot and Steg 2008, 2010; Steg, Dreijerink and Abrahamse 2005]. We will first explain the concept values, and elaborate on the distinction between egoistic, altruistic and biospheric values in environmental contexts. Then, we will discuss why these three types of values may also be distinguished in Hungary, and how these values are related to a specific type of beliefs, that is, personal norms towards different pro-environmental behaviours.

\section{Value theory}

Relationships between values, behaviour-specific beliefs, such as personal norms, and behaviour have been studied extensively in the environmental domain [e.g. Corraliza and Berenguer 2000; García Mira et al. 2003; Gärling et al. 2003; Schultz 
et al. 2005; Stern and Dietz 1994; Thøgersen and Ölander 2002; Verplanken and Holland 2002]. Most of these studies have used values from Schwartz's value theory [1992, 1994, 2008]. Schwartz proposed a general and comprehensive taxonomy of 56 values. Participants taking Schwartz's value survey are requested to rate each value on a 9-point scale measuring their importance as a guiding principle in their life. One of the main dimensions underlying the value structure identified by Schwartz reflects a distinction between self-transcendent values that stress the interests of others, and self-enhancement values that emphasise self-interest. This dimension appears to be particularly relevant for explaining different types of environmental beliefs, norms, and behaviours, because environmental choices often involve a conflict between immediate individual gains and longterm collective interests [de Groot and Steg 2009; Nordlund and Garvill 2002, 2003; Thøgersen and Ölander 2002; Stern 2000]. Most studies have found that people who strongly endorse self-transcendent values have stronger pro-environmental beliefs, norms, and act more pro-environmentally, while the opposite is true for people who more strongly endorse self-enhancement values [e.g. Cameron, Brown and Chapman 1998; Gärling et al. 2003; Kalof et al. 1999; Karp 1996; Nordlund and Garvill 2002, 2003; Schultz et al. 2005; Stern 2000; Stern, Dietz and Guagnano 1998; Thøgersen and Ölander 2002].

\section{A distinction between biospheric and altruistic values?}

In literature on environmental ethics, various scholars have argued that humans may (fail to) act pro-environmentally based on the extent to which they endorse the biosphere and nature for the intrinsic value itself [Leopold 1949; Naess 1989; Reid 1962; Singer 1975]. This implies that we should distinguish two types of selftranscendence values: biospheric values that reflect a key concern with the quality of nature and the environment for its own sake, and altruistic values that particularly reflect an interest for the well-being of other human beings [e.g. de Groot and Steg 2007, 2008, 2010; Schultz 2001; Steg et al. 2005; Stern 2000; Stern, Dietz and Guagnano 1998]. Based on this assumption, scholars have proposed three different types of values for understanding beliefs and actions in the environmental domain: egoistic, altruistic and biospheric values [de Groot and Steg 2007, 2008, 2010; Grønhøj and Thøgersen 2009; Nilsson, von Borgstede and Biel 2004; Steg, Dreijerink and Abrahamse 2005; Stern 2000; Stern and Dietz 1994; Stern, Dietz and Kalof 1993]. People with strong egoistic values will especially consider the consequences of environmental choices for them personally: when the perceived benefits exceed the perceived costs they have pro-environmental preferences and will act pro-environmentally and vice versa. People who strongly endorse altruistic values will base their decisions related to the environment on the perceived costs and benefits for other people. Finally, people who strongly value the biosphere and the environment will mainly base their choices on the perceived costs and benefits of actions for the ecosystem and biosphere as a whole. 
Studies have shown that egoistic, altruistic and biospheric values can indeed be clearly distinguished empirically [de Groot and Steg 2007, 2008, 2010; Grønhøj and Thøgersen 2009; Nilsson, von Borgstede and Biel 2004; Steg, Dreijerink and Abrahamse 2005; Steg et al. 2011]. Although altruistic and biospheric values are positively correlated because both reflect 'self-transcendent' values, they can be distinguished empirically via Confirmatory Factor Analysis suggesting that they indeed tap on two different types of self-transcendence values [e.g. de Groot and Steg 2007, 2008; Nilsson, von Borgstede and Biel 2004]. Often altruistic and biospheric values are positively related to environmental beliefs, norms, and actions, because such beliefs, norms, and actions generally benefit the well-being of others and the biosphere [e.g. de Groot and Steg 2007, 2008]. However, in general, biospheric values are stronger predictors of environmental beliefs, norms, and behaviours than are altruistic values [de Groot and Steg 2007, 2008; Nilsson, von Borgstede and Biel 2004; Steg, Dreijerink and Abrahamse 2005], probably because environmental behaviours are generally perceived to benefit more strongly the biosphere than other people. This suggests that it is indeed relevant to consider biospheric values independently from altruistic values in research.

However, under some circumstances altruistic and biospheric values may contribute uniquely in explaining certain environmental beliefs, norms, and actions, especially when altruistic and biospheric consequences of behavioural choices conflict [de Groot and Steg 2008]. For example, when having to choose whether to donate to an environmental or humanitarian organisation, or voting for a green or a social party, biospheric and altruistic values can predict preferences and choices in the opposite direction. To illustrate, people with strong altruistic values were more likely to donate to humanitarian rather than environmental organisations, while the opposite was true for those with strong biospheric values [de Groot and Steg 2008]. Because of the strong predictive power of biospheric values and possible unique explanatory power of biospheric and altruistic values, it seems relevant to study the role of biospheric next to altruistic values in the environmental domain.

\section{Biospheric values in Hungary?}

Thus far, the significance of biospheric values has mainly been demonstrated in Western European countries [see, e.g., de Groot and Steg 2007; Nilsson, von Borgstede and Biel 2004; Steg, Dreijerink and Abrahamse 2005]. Can biospheric values be distinguished as a separate value cluster in a post-socialist country such as Hungary as well?

Hungary may be regarded as a different culture than other Western and Southern European cultures. For example, Hungary shows more overlap with other post-socialist European countries including the Czech Republic, Slovenia, and Estonia on most values as defined in Schwartz's value theory than with 
Western or Southern European countries or with English speaking countries [Schwartz 2008]. Also, for environmental aspects, such as environmental awareness, Hungarians normally respond differently from other European cultures and countries. Depending on the specific measurement, the level of environmental awareness seems to differ between Hungary and the countries in which the three-way distinction has been found [e.g. Esty et al. 2005; European Commission 2005, 2006; Franzen 2003]. For example, environmental awareness was somewhat lower in Hungary than in countries such as Sweden, but very similar to countries such as the Netherlands and the United Kingdom [European Commission 2005, 2006; Franzen 2003]. If corrected for gross domestic product per capita (GDP), Hungarians tend to invest more in pollution control and other environmental amenities compared to countries such as the Netherlands, Belgium and the United Kingdom, but less than in European countries such as Sweden and Norway [Esty et al. 2005]. Thus, Hungary is regarded as a different culture compared to other European countries in which the distinction between egoistic, altruistic, and biospheric values was found. Are biospheric values relevant for understanding environmental beliefs and norms in Hungary?

There are indications that biospheric values could indeed be distinguished as a separate type of self-transcendence values in Hungary. Schwartz [1992] argued that, although people may differ in how strongly they endorse various values, the structure of values is universal [see also, e.g., Bilsky, Janik and Schwartz 2011; Schwartz 1994; Schwartz and Bardi 2001; Schwartz et al. 2001]. To illustrate, Schwartz [2008] showed that East-Central and Baltic Europe, including post-socialist countries such as Hungary, prioritise most value clusters differently compared to countries in Western Europe (e.g. Sweden, Germany, the Netherlands). However, Schwartz also showed that the same value clusters could be distinguished in these countries despite the fact that they were prioritised differently. Therefore, the same type of value clusters should be found despite cultural differences.

In Schwartz's studies no distinction has been made between biospheric and altruistic values. This may be due to the selection of values included in his value instrument. For example, in studies based on Schwartz's value theory [1992] only few biospheric value items were included; consequently, it will be difficult to find a separate biospheric value cluster via factor analyses [see, e.g., de Groot and Steg 2008]. In this study, we are going to examine whether Schwartz's value theory will hold when distinguishing biospheric from altruistic values. That is, will the clustering of biospheric and altruistic values be universally applicable, independent of cultural differences between countries on such values? In line with Schwartz's value theory, we expect to find a distinction between altruistic and biospheric values, both reflecting self-transcendent values, in Hungary, despite cultural differences. 


\section{Egoistic, altruistic, and biosperic values and personal norms}

When biospheric values may be distinguished from altruistic values in Hungary, then we would also expect those values to be similarly related to environmental beliefs such as personal norms [cf. Schultz and Zelezny 1999]. Typically, values do not influence environmental behaviour directly, but rather indirectly, via behaviour-specific beliefs, such as personal norms [de Groot and Steg 2007, 2008; Nordlund and Garvill 2002, 2003; Steg, Dreijerink and Abrahamse 2005; Stern 2000]. Personal norms are assumed to be rooted in values [Schwartz 1977; Stern 2000]. That is, people feel morally obliged to act in accordance with their prevalent values. Personal norms towards various types of environmental behaviours have shown to be strong determiners of engagement in environmental behaviours [de Groot and Steg 2009; Schwartz 1977; Steg, Dreijerink and Abrahamse 2005; Steg and de Groot 2010; Stern 2000].

Studies have shown that biospheric values are typically more predictive of personal norms than are altruistic and egoistic values. For example, De Groot and Steg [2007] found that egoistic, altruistic, and biospheric values explained $21 \%$ of the variance in personal norms to reduce car use in five different European countries. Biospheric values were by far the best predictor in all countries: stronger biospheric values were related to stronger feelings of personal obligation to reduce car use. Egoistic values contributed to the explanation of personal norms as well, but this relationship was weaker and in the opposite direction. Steg and colleagues [Steg, Dreijerink and Abrahamse 2005] showed that of the three values, only biospheric values contributed directly to explaining personal norms towards reducing energy consumption after correcting for the contribution of other behaviour-specific beliefs towards energy saving.

We will examine how egoistic, altruistic and biospheric values account for personal norms towards a diversity of environmental behaviours in Hungary. We expect that biospheric values are a strong predictor for explaining personal norms towards environmental behaviour in Hungary as well.

\section{Aim of the study}

This study aims to answer two questions. First, can we reliably distinguish egoistic, altruistic, and biospheric values as separate value clusters in Hungary? Second, are biospheric values a significant predictor of personal norms towards environmental behaviours in Hungary? We assume that biospheric values can be distinguished empirically from egoistic and altruistic values in Hungary, despite differences in culture between Hungary and other countries in which the distinction has been found. Furthermore, we expect that biospheric values will be strongly and positively related to different personal norms towards environmental behaviours in Hungary. 
To test the robustness of our findings, we tested our hypotheses in two largescale questionnaire studies in Hungary. In both studies, we examined whether the three types of values can be distinguished empirically. Moreover, we investigated how values, and particularly biospheric values, were related to a wide range of personal norms towards environmental behaviour. We included personal norms towards curtailment behaviours (e.g. turning off lights, reducing car use), efficiency behaviours (e.g. purchasing energy-efficient light bulbs) and the adoption of sustainable energy resources [Gardner and Stern 2002] in different environmental domains, that is, focusing on actions in the home (e.g. turning off lights) and mobility (e.g. reducing car use). In doing so, we could test the generalisability of our results across different types of behaviours in different domains.

\section{Method}

\section{Respondents and procedure}

Two online questionnaire studies were conducted among large samples of the Hungarian population. Participants were selected by Advanced Market Research (AMR), a consumer research company that has its own panel of Hungarian citizens who have indicated that they are approachable for questionnaire studies. AMR contacted members of this panel on the basis of a number of stratification criteria (i.e. gender, age, household income, education level, marital status and household composition) to aim for a varied sample for the population of Hungary. Participants could only participate in one questionnaire study.

Both questionnaires included the same value scale (see below). Furthermore, questions were included on personal norms towards different types of environmental behaviour; these questions differed across the two questionnaires. A total of 2201 participants completed the questionnaires, of which 1100 in Questionnaire 1 and 1101 in Questionnaire 2. A number of participants had to be removed from the data set because of irregular answering patterns. ${ }^{1}$ Participants who were included in the dataset did not differ substantially from those who were excluded in socio-demographics. We analysed both data sets separately ( $N=856$ for Questionnaire 1; $N=840$ for Questionnaire 2).

\footnotetext{
${ }^{1}$ To filter out questionnaires that were unsuitable for inclusion in the analysis, the following criteria were used: participants who answered more than two-thirds of all questions from one question battery identically were removed and participants who filled out improbable answers in quality-control questions that requested participants to fill out a particular number were removed. Most participants who were removed used identical answering patterns in several question batteries, indicating that they did not complete the questionnaire seriously. The chosen criteria were strict, which is reflected in the number of participants who are excluded from the analysis, but this ensured that the results are not affected by participants who did not answer the questions seriously.
} 
Table 1. Socio-demographics for the Hungarian population and two samples

\begin{tabular}{|c|c|c|c|c|}
\hline & & $\begin{array}{l}\text { Hungarian } \\
\text { population* }\end{array}$ & $\begin{array}{c}\mathrm{Q} 1 \\
(N=856)\end{array}$ & $\begin{array}{c}\text { Q2 } \\
(N=840)\end{array}$ \\
\hline \multirow[t]{6}{*}{ Age } & 15-17 years & $4.4 \%$ & $21.6 \%$ & $24.2 \%$ \\
\hline & 18-29 years & $20.9 \%$ & $22.1 \%$ & $21.1 \%$ \\
\hline & 30-39 years & $17.0 \%$ & $26.6 \%$ & $26.9 \%$ \\
\hline & 40-49 years & $15.7 \%$ & $18.9 \%$ & $17.9 \%$ \\
\hline & $50-59$ years & $16.8 \%$ & $9.0 \%$ & $7.3 \%$ \\
\hline & $60+$ & $25.3 \%$ & $1.8 \%$ & $2.7 \%$ \\
\hline \multirow[t]{2}{*}{ Gender } & Male & $46.8 \%$ & $48.4 \%$ & $48.9 \%$ \\
\hline & Female & $53.2 \%$ & $51.6 \%$ & $51.1 \%$ \\
\hline \multirow{5}{*}{$\begin{array}{l}\text { Persons per } \\
\text { household }\end{array}$} & 1-person & $20.5 \%$ & $12.3 \%$ & $8.9 \%$ \\
\hline & 2-person & $30.6 \%$ & $25.0 \%$ & $25.8 \%$ \\
\hline & 3-person & $20.8 \%$ & $24.6 \%$ & $22.9 \%$ \\
\hline & 4-person & $17.3 \%$ & $25.1 \%$ & $27.6 \%$ \\
\hline & 5-person or more & $10.7 \%$ & $13.0 \%$ & $14.8 \%$ \\
\hline \multirow{5}{*}{$\begin{array}{l}\text { Education } \\
\text { level }\end{array}$} & Incomplete primary & $8.1 \%$ & $1.7 \%$ & $1.9 \%$ \\
\hline & Primary (6-14 yrs) & $29.9 \%$ & $21.4 \%$ & $19.6 \%$ \\
\hline & Vocational (14-18 yrs) & $21.1 \%$ & $16.6 \%$ & $16.4 \%$ \\
\hline & Secondary (14-18 yrs) & $27.9 \%$ & $37.9 \%$ & $40.7 \%$ \\
\hline & Higher education (18-) & $12.9 \%$ & $22.4 \%$ & $21.3 \%$ \\
\hline \multirow{6}{*}{$\begin{array}{l}\text { Household } \\
\text { income }\end{array}$} & $<1000$ euros/month & & $81.2 \%$ & $81.1 \%$ \\
\hline & 1000-2000 euros/month & & $15.5 \%$ & $16.0 \%$ \\
\hline & 2000-3000 euros/month & & $1.4 \%$ & $1.3 \%$ \\
\hline & 3000-4000 euros/month & & $0.9 \%$ & $0.9 \%$ \\
\hline & 4000-5000 euros/month & & $0.3 \%$ & $0.1 \%$ \\
\hline & $>5000$ euros/month & & $0.7 \%$ & $0.6 \%$ \\
\hline \multirow[t]{3}{*}{ Settlement type } & Cities/capital city & $35.6 \%$ & $38.6 \%$ & $37.6 \%$ \\
\hline & Town & $32.0 \%$ & $37.5 \%$ & $38.5 \%$ \\
\hline & Village & $32.4 \%$ & $23.9 \%$ & $23.9 \%$ \\
\hline
\end{tabular}

Notes: *Age $15+. \wedge$ There is no information available on household income in the Hungarian population. The average net mean salary was 382 euros per month [OECD $2006]$. Therefore, we would expect a relatively high proportion $(\sim 80 \%)$ of the Hungarian population to be categorised in the '< 1000 euros $/$ month'. Q1 = Questionnaire 1; Q2 = Questionnaire 2.

Source: Ipsos-GfK: Nemzeti Média Analízis (2010). 
Table 1 provides an overview of the socio-demographic characteristics of the participants who were included in the data analyses for the two samples. When comparing our samples with socio-demographics of the Hungarian population (Ipsos-GfK: Nemzeti Média Analízis 2010), ${ }^{2}$ people under 30 years were over-represented in both samples (approximately $45 \%$ in both samples instead of $25 \%)$, while older people (50+) were under-represented $(11 \%$ and $10 \%$ in the samples and $40 \%$ in the general Hungarian population). Furthermore, the level of education of the samples differed somewhat from the national average: a relatively high percentage of people in our sample had finished high school (38\% and $41 \%$ versus $28 \%$ ) or higher education ( $22 \%$ and $21 \%$ versus $13 \%)$. Finally, relatively more people in our sample lived in smaller towns (approximately $38 \%$ in both samples versus $32 \%$ ), while the share of people living in villages was underrepresented ( $24 \%$ in both samples versus $32 \%$ ). The proportion of people living in cities and Budapest was representative for the Hungarian population. Thus, our sample is not fully representative for the Hungarian population.

\section{Questionnaire}

Both questionnaires were part of a larger study which investigated the barriers and opportunities to reduce household energy consumption (see www.barenergy.eu). Values and personal norms were included in both questionnaires together with other questions on energy consumption as part of this larger study.

Values were assessed by means of a short version of Schwartz's value survey [1992] developed by de Groot and Steg [2008] which was included at the very beginning of both questionnaires. This value scale consists of thirteen values. Figure 1 shows how the thirteen value items are theoretically related to the egoistic, altruistic and biospheric value constructs. Respondents indicated to what extent the value-items were important 'as a guiding principle in their lives' on a 9-point scale ranging from -1 'opposed to my values', 0 'not important' to 7 'extremely important'. Following Schwartz, respondents were urged to vary scores as much as possible and to rate no more than two values as extremely important.

Personal norms. We included personal norms towards five different types of environmental behaviours, that is, personal norms towards: (1) using more sustainable energy sources, (2) reducing total car use, (3) reducing car use for short trips, (4) using energy-efficient light bulbs, and (5) turning off the lights. The first two were included in Questionnaire $1(N=856)$, while the other three measures were included in Questionnaire $2(N=840)$. All personal norms were measured with three items that were similar and only varied in the behaviour it focused on. For example, the items included to measure personal norms towards reducing

\footnotetext{
2 Ipsos-GfK: Nemzeti Média Analízis. 2010 (National Readership Study). Data obtained directly from Ipsos Group's database on 21 October 2009 (http://www.ipsos.hu/site/ gfk-ipsos-stabilan-magas-r-di-hallgatotts-g/).
} 


\section{Figure 1. Theoretical model of how value-items are related to egoistic, altruistic and biospheric value scales}

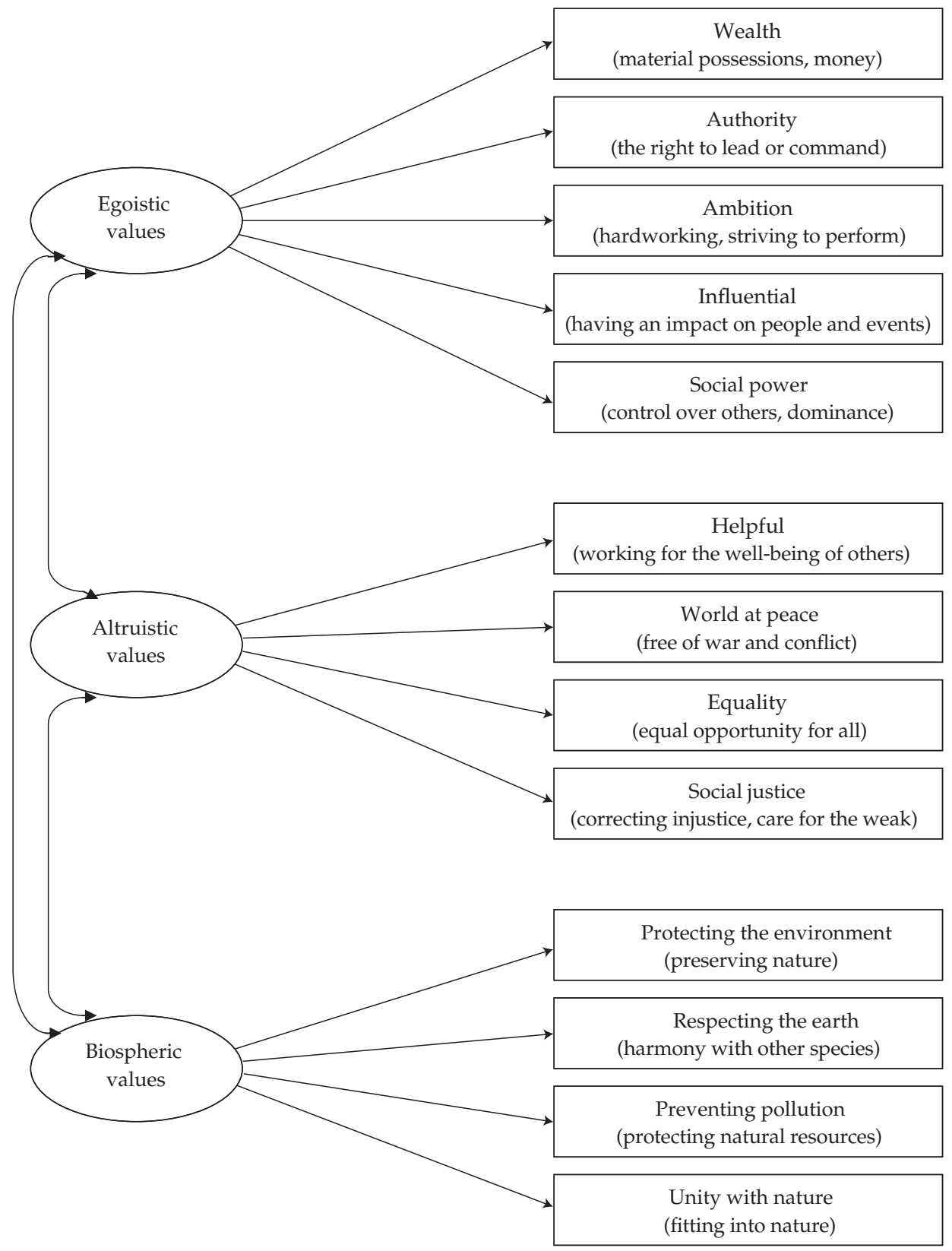

Source: de Groot and Steg [2008]. 
Table 2. Means, standard deviations and Cronbach's alpha for personal norms

\begin{tabular}{lccc}
\hline Personal norms towards...: & M & SD & Alpha \\
\hline Increasing the use of sustainable energy sources & 4.5 & 1.6 & .74 \\
Reducing the number of car trips & 3.7 & 1.6 & .77 \\
Reducing the number of car use for short trips & 4.1 & 1.6 & .81 \\
Purchasing energy-efficient light-bulbs & 4.3 & 1.5 & .74 \\
Turning off lights & 4.6 & 1.7 & .84 \\
\hline
\end{tabular}

Source: Authors' calculations.

the amount of car trips included: 'I feel morally obliged to reduce the percentage of trips I travel by car', 'I would violate my principles if I would not try to reduce the percentage of journeys I travel by car', and 'I feel guilty if I do not try to reduce the percentage of journeys I travel by car'. Respondents indicated to what extent they agreed with each personal norm item on a seven-point scale ranging from 'strongly disagree' (1) to 'strongly agree' (7). Mean scores, standard deviations and alpha reliabilities were computed for all constructs (see Table 2).

\section{Analyses}

As we had clear theoretical predictions of the structure of the values, we conducted confirmatory factor analysis to test the underlying factor structure in the Hungarian samples. Separate analyses for each of the two samples were conducted to examine the robustness of the distinction between the three value types in Hungary. Following de Groot and Steg [2007, 2008], we used the multiple group method (MGM), a specific and robust type of CFA, to verify whether the data supported the groupings of value items into the three value scales (i.e. egoistic, altruistic, and biospheric values). Following Nunnally [1978], in the MGM, we first defined components (i.e. value clusters) on theoretical grounds. For this purpose, we computed the mean score of value items supposedly related to the relevant value scales. Next, correlations were computed between value items and the three value scales. For items included in a scale, the correlation coefficients were corrected for 'self-correlation', that is, the fact that items automatically correlate high with components in which they take part. Finally, we verified whether the value items indeed correlated strongest with the component to which they were assigned to on theoretical grounds. It is assumed that the factor structure (i.e. the grouping of value items into egoistic, altruistic and biospheric value scales) is supported when items correlate highest with the scale they are assigned to on theoretical grounds after correcting for self correlations [see Nunnally 1978]. To investigate whether biospheric values are important predictors of personal 
Table 3. Corrected correlations between value items and value scales via the multigroup method for Questionnaire $1(N=856)$ and $2(N=840)$

\begin{tabular}{|c|c|c|c|c|c|c|}
\hline \multirow{2}{*}{$\begin{array}{l}\text { Value clusters } \\
\text { Value items }\end{array}$} & \multicolumn{2}{|c|}{ Egoistic } & \multicolumn{2}{|c|}{ Altruistic } & \multicolumn{2}{|c|}{ Biospheric } \\
\hline & Q1 & Q2 & Q1 & Q2 & Q1 & Q2 \\
\hline \multicolumn{7}{|l|}{ Egoistic values: } \\
\hline 1. Wealth & .28 & .30 & .08 & .08 & .12 & .12 \\
\hline 2. Authority & .55 & .55 & .10 & .09 & .07 & .07 \\
\hline 3. Ambition & .33 & .30 & .44 & .47 & .37 & .43 \\
\hline 4. Influential & .57 & .52 & .23 & .20 & .19 & .24 \\
\hline \multirow[t]{2}{*}{ 5. Social power } & .58 & .55 & .11 & .16 & .12 & .14 \\
\hline & Alpha $=.70$ & Alpha $=.69$ & & & & \\
\hline
\end{tabular}

Altruistic values:

$\begin{array}{lllllll}\text { 1. Helpful } & .22 & .28 & .41 & .44 & .39 & .42 \\ \text { 2. } \begin{array}{l}\text { A world at } \\ \text { peace }\end{array} & .14 & .16 & .44 & .47 & .48 & .52 \\ \text { 3. Equality } & .21 & .18 & .58 & .59 & .49 & .48 \\ \text { 4. Social justice } & .22 & .23 & .58 & .63 & .47 & .48\end{array}$

Alpha $=.71 \quad$ Alpha $=.74$

Biospheric values:

1. Protecting the environment

.19

.25

.50

.53

.69

.72

2. Respecting the earth

.22

.22

.58

.54

.72

.74

3. Preventing pollution

.21

.26

.50

.55

.74

.78

4. Unity with nature

.22

.26

.51

.55

.70

.74

Alpha $=.86$ Alpha $=.88$

Notes: For each item, the highest correlation is printed in bold. Correlations are corrected for 'self-correlations'. Q1 = Questionnaire 1; Q2 = Questionnaire 2.

Source: Authors' calculations. 
norms in Hungary, relationships between egoistic, altruistic and biospheric values and the five types of personal norms were investigated via multiple regression analyses.

\section{Results}

The distinction between egoistic, altruistic and biospheric values

Table 3 shows the results of the MGM for both studies. The results largely confirmed the grouping of the value items into the three value clusters in Hungary. In general, the egoistic values correlated most strongly with the egoistic value scale, the altruistic values correlated most strongly with the altruistic value scale, and the biospheric values correlated most strongly with the biospheric value scale in both samples. Two minor discrepancies were found for both samples. First, the altruistic item 'a world at peace' correlated slightly stronger with the biospheric value scale than with the altruistic value scale after correction for selfcorrelations. Second, the egoistic item 'ambition' correlated stronger with both the altruistic and the biospheric scales than with the egoistic scale after correction for self-correlations. In Questionnaire 1, Cronbach's alpha was .70 for the egoistic $(M=2.9, S D=1.3), .71$ for the altruistic $(M=4.9, S D=1.3)$, and .86 for the biospheric value scale $(M=5.1, S D=1.4)$. In Study 2, Cronbach's alpha was .69 for the egoistic $(M=3.2, S D=1.2), .74$ for the altruistic $(M=4.9, S D=1.3)$, and .88 for the biospheric value scale $(M=5.1, S D=1.4)$.

As in previous studies, the altruistic and biospheric value scales were positively correlated (Questionnaire 1: $r=.62, p<.001$; Questionnaire 2: $r=.63$, $p<.001)$. The correlation between the egoistic and altruistic value scale was weaker but significant as well (Questionnaire 1: $r=.28, p<.001$; Questionnaire 2: $r=.29, p<.001$ ), while the correlation between the egoistic and biospheric value scale was .25 $(p<.001)$ for Questionnaire 1 and $.29(p<.001)$ for Questionnaire 2. Thus, the results of the MGM, reliability analyses, and correlations between the sub-scales are similar in both samples.

\section{Relationships between values and personal norms}

Table 4 shows to what extent and how values predict the five types of personal norms. The three values explained $13 \%$ of the variance in personal norms towards adopting sustainable energy sources $(F(3,852)=43.47, p<.001)$. Only biospheric value orientations contributed significantly to this model. Those with strong biospheric values felt a stronger moral obligation to adopt sustainable energy sources $(\beta=.32, p<.001)$.

Egoistic, altruistic, and biospheric values explained $14 \%$ of the variance in personal norms towards reducing car use $(F(3,852)=45.95, p<.001)$. Again, 
Table 4. Multiple regression analyses for explaining personal norms with egoistic, altruistic and biospheric values

\begin{tabular}{|c|c|c|c|c|c|c|}
\hline & $\beta$ & $t$ & $R^{2} a d j$ & $F$ & $d f$ & $p$ \\
\hline PN towards adopting SES & & & .13 & 43.47 & 3,852 & .000 \\
\hline Egoistic values & -.03 & -0.83 & & & & .405 \\
\hline Altruistic values & .07 & 1.66 & & & & .097 \\
\hline Biospheric values & .32 & 7.91 & & & & .000 \\
\hline $\begin{array}{l}\text { PN towards reducing } \\
\text { general CT }\end{array}$ & & & .14 & 45.95 & 3,852 & .000 \\
\hline Egoistic values & .02 & 0.58 & & & & .561 \\
\hline Altruistic values & .15 & 3.66 & & & & .000 \\
\hline Biospheric values & .26 & 6.36 & & & & .000 \\
\hline $\begin{array}{l}\text { PN towards reducing short } \\
\text { distance } C T\end{array}$ & & & .09 & 28.14 & 3,836 & .000 \\
\hline Egoistic values & .03 & 0.96 & & & & .340 \\
\hline Altruistic values & .00 & 0.10 & & & & .924 \\
\hline Biospheric values & .29 & 6.72 & & & & .000 \\
\hline$P N$ towards using ELB & & & .12 & 39.34 & 3,836 & .000 \\
\hline Egoistic values & .02 & 0.46 & & & & .645 \\
\hline Altruistic values & -.04 & -1.02 & & & & .308 \\
\hline Biospheric values & .37 & 8.83 & & & & .000 \\
\hline $\begin{array}{l}\text { PN towards turning off } \\
\text { lights }\end{array}$ & & & .06 & 17.68 & 3,836 & .000 \\
\hline Egoistic values & .04 & 1.02 & & & & .308 \\
\hline Altruistic values & -.01 & -0.19 & & & & .850 \\
\hline Biospheric values & .24 & 5.45 & & & & .000 \\
\hline
\end{tabular}

Notes: PN = personal norms; SES = sustainable energy sources; CT = car trips;

$\mathrm{ELB}=$ energy-efficient light bulbs. We checked the variance inflation factor (VIF) and the tolerance statistic on problems related to multicollinearity. These statistics did not indicate any cause for concern.

Source: Authors' calculations. 
biospheric values contributed most strongly to the model: the more people valued the biosphere and environment, the stronger their personal norms towards reducing their car use $(\beta=.26, p<.001)$. Furthermore, altruistic values contributed uniquely to the explanation of personal norms towards reducing car use as well, although relationships were weaker. The stronger people valued other people and the community, the more they felt morally obliged to reduce car use $(\beta=.15, p<.001)$.

Values also predicted personal norms towards reducing car trips for short distances $\left(R^{2}=.09, F(3,836)=28.42, p<.001\right)$, using energy-efficient light bulbs $\left(R^{2}=.12, F(3,836)=39.34, p<.001\right)$, and turning off lights $\left(R^{2}=.06, F(3,836)=17.68\right.$, $p<.001)$. Again, only biospheric values significantly contributed to the explanation of the personal norms towards these three types of environmental behaviours. Participants who strongly valued nature and the environment expressed stronger personal norms towards reducing car trips for short distances $(\beta=.29$, $p<.001)$, using energy-efficient light bulbs $(\beta=.37, p<.001)$, and turning off lights $(\beta=.24, p<.001)$.

\section{Discussion and conclusion}

Is the significance of biospheric values a Western European phenomenon, or can biospheric values also be distinguished from altruistic values in Hungary? Also, are egoistic, altruistic and biospheric values related to behaviour-specific beliefs and norms, such as personal norms, in Hungary like in other (Western European) countries? These were the key questions addressed in this study.

We found that egoistic, altruistic and biospheric values can be distinguished empirically in Hungary. We found the same patterns of results in two different samples of the Hungarian population which suggest that our results were rather robust. The multi-group method revealed that, in general, each value correlated strongest with the value orientation to which it was assigned on theoretical grounds. Although altruistic, and biospheric values were correlated, most altruistic values correlated most strongly with the altruistic value scale, and biospheric values with the biospheric value scale. The internal reliability of the three value scales was acceptable to good. Especially the reliability of the biospheric value scale was high in both samples. Therefore, this study provides a first validation of the distinction between egoistic, altruistic and biospheric values in Hungary.

There were two minor deviations from the initial theoretical model. First, the altruistic item 'a world at peace' correlated slightly stronger with the biospheric value scale than with the altruistic value scale after correcting for self-correlations. Past studies also have shown that this altruistic value-item sometimes correlates strongly with the biospheric value scale [e.g. de Groot and Steg 2007, 2008]. Apparently, 'a world at peace' is associated both with valuing society and other people and valuing natural and biospheric aspects in most countries and 
cultures. Second, the egoistic item 'ambition' correlated more strongly with both the altruistic and biospheric value scales than with the egoistic value scale. This is quite a distinctive but consistent finding in both Hungarian samples which we will further discuss below. Except these small deviations, our results largely fit the theoretical model and therefore our findings suggest that the structure of values is indeed similar across cultures, which is in line with value theory [e.g. Bilsky, Janik and Schwartz 2011; Schwartz 1994; Schwartz and Bardi 2001; Schwartz et al. 2001]. That is, we found that egoistic, altruistic, and biospheric values can be distinguished in Hungary as well, similar to studies in other countries and cultures [see, e.g., de Groot and Steg 2007, 2008]. As both biospheric and altruistic values reflect self-transcendent values [Schwartz 1994], it is not surprising that both types of values were correlated. Despite this, the empirical distinction between altruistic and biospheric values was found in both samples.

Our results showed that the internal consistencies of the egoistic, altruistic, and biospheric value scales were acceptable to good in both samples. As mentioned above, the value item 'ambition' was more strongly related to both the altruistic and the biospheric value scales than to the egoistic scale. Apparently, being ambitious for Hungarians is not necessarily related with an emphasis on self-interests, but more with a focus on societal and environmental interests. A study by de Groot and Steg [2007] shows a similar result for their Czech sample: 'being ambitious' was strongly related to the altruistic value scale, especially compared to the other countries (i.e. Austria, Italy, the Netherlands, and Sweden). Czech Republic and Hungary show a lot of overlap in the cultural values they share [Schwartz 2008]. Therefore, it may be that people from post-socialist countries value and interpret ambition in a different way than people from Western and Southern European countries. Future studies should examine this finding in more detail.

Importantly, our findings suggest that Hungarians not only distinguish caring for nature and the environment from caring for other people and society as such, but that these values are translated into feelings of moral obligation to protect the environment as well. Indeed, as hypothesised, biospheric values strongly contributed to the explanation of a range of personal norms towards environmental behaviours. More specifically, biospheric values were the only significant predictor of four of the five types of personal norms included in our studies, and were the strongest predictor for all five types of personal norms. Thus, the same pattern of results was replicated using five types of personal norms towards a variety of pro-environmental actions, suggesting that our results are robust. Our results suggest that biospheric values are indeed highly relevant to understand environmental beliefs, norms, and actions in Hungary. This is in line with research conducted in Western Europe indicating that biospheric values are generally more strongly and consistently related to personal norms towards environmental behaviours than are altruistic and egoistic values [de Groot and Steg 2007; Nordlund and Garvill 2003; Steg, Dreijerink and Abrahamse 2005]. 
Our results further showed that altruistic and biospheric values can contribute uniquely towards explaining personal norms towards car use in Hungary. These results correspond with other scholars arguing that although altruistic and biospheric values will often tap into similar aspects of environmental beliefs, norms and behaviours (i.e. caring for the interests of others or the environment), they may sometimes contribute uniquely to such aspects [e.g. de Groot and Steg 2008; Schultz et al. 2005; Stern 2000]. For example, de Groot and Steg [2010] also found that both altruistic and biospheric values contributed uniquely when choosing a car based on environmental performance (Study 2) and donating to an environmental organisation (Studies 1 and 2). The unique explanatory power of biospheric and altruistic values implies that it is relevant to include both biospheric and altruistic values in environmental research.

Although we tried to aim for representative samples, our samples were not fully representative of the Hungarian population. For follow-up research aiming to compare mean scores across various countries and cultures, representative samples should be used. However, for the aim of our study, not fully representative samples were less problematic because we were only interested in examining relationships between variables. It is highly unlikely that the relationships between values vary across samples [de Groot and Steg 2007; Schultz et al. 2005]. Therefore, we think that our large and varied samples were sufficient for the aim of this study, that is, to test whether biospheric values can be distinguished as a separate value cluster from altruistic values in post-socialist Hungary, and examining relationships between values and personal norms. Even though Hungary differs from Western countries on historical, economic, political and cultural grounds, the three-way distinction found in Western countries was clearly validated. Also, egoistic, altruistic, and biospheric values appeared to be similarly related to personal norms as in studies conducted in Western Europe. This suggests that it is especially relevant to study biospheric values when explaining environmental beliefs, norms and behaviour in different cultural or national contexts.

JUDITH I.M. DE GROOT works as a senior lecturer in psychology at Bournemouth University, UK. Her research interests include explaining and changing moral behaviours, such as pro-environmental behaviour. A main focus of her research includes how values and norms may be used to promote moral behaviours.

LINDA STEG is professor of environmental psychology at the University of Groningen. Her research focuses on understanding and changing environmental behaviour, with a specific interest in the role of values, norms, and normative considerations.

MARTIN KeIZER is pursuing a doctoral degree in psychology at the University of Groningen. His research interests include the role of morality in promoting pro-environmental behaviour and the influence of contextual factors on motivation. 
ANDREA FARSANG is a PhD candidate and research affiliate in the Department of Environmental Sciences and Policy at the Central European University. Her research interests include the role of emotions and values in promoting behaviour change towards sustainability.

Alan WatT is head of the Department of Environmental Sciences and Policy at the Central European University. A philosopher by background, his research interests in the environmental field are primarily connected with exploring environmental values.

\section{References}

Bilsky, Wolfgang, Michael Janik and Shalom H. Schwartz. 2011. 'The Structural Organization of Human Values-Evidence from Three Rounds of the European Social Survey (ESS).' Journal of Cross-Cultural Psychology 42 (5): 759-776.

Cameron, Linda D., Paul M. Brown and Judith G. Chapman. 1998. 'Social Value Orientations and Decisions to Take Proenvironmental Action.' Journal of Applied Social Psychology 28: 675-697.

Corraliza, José A. and Jaime Berenguer. 2000. ‘Environmental Values, Beliefs, and Actions. A Situational Approach.' Environment and Behavior 32: 832-848.

de Groot, Judith I. M. and Linda Steg. 2007. 'Value Orientations and Environmental Beliefs in Five Countries: Validity of an Instrument to Measure Egoistic, Altruistic and Biospheric Value Orientations.' Journal of Cross-Cultural Psychology 38: 318-332.

de Groot, Judith I. M. and Linda Steg. 2008. 'Value Orientations to Explain Environmental Attitudes and Beliefs: How to Measure Egoistic, Altruistic and Biospheric Value Orientations.' Environment and Behavior 40: 330-354.

de Groot, Judith I. M. and Linda Steg. 2009. 'Mean or Green? Values, Morality and Environmental Significant Behavior.' Conservation Letters 2: 61-66.

de Groot, Judith I. M. and Linda Steg. 2010. 'Relationships Between Value Orientations, Self-determined Motivational Types and Pro-Environmental Behavioural Intentions.' Journal of Environmental Psychology 30: 368-378.

Dunlap, Riley E., J. Kieth Grieneeks and Milton Rokeach. 1983. 'Human Values and Pro-Environmental Behaviour.' Pp. 145-168 in Energy and Material Resources: Attitudes, Values, and Public Policy, edited by W. David Conn. Boulder, CO: Westview Press.

Esty, D. C., M. Levy, T. Srebotnjak and A. de Sherbinin. 2005. 2005 Environmental Sustainability Index: Benchmarking National Environmental Stewardship. New Haven, CT: Yale Center for Environmental Law \& Policy.

European Commission (EC). 2005. Special Eurobarometer 217. The Attitudes of European Citizens towards the Environment. Luxembourg: Office for Official Publications of the European Commission.

European Commission (EC). 2006. Attitudes towards Energy. A Special Eurobarometer. Brussels: European Commission.

Franzen, A. 2003. 'Environmental Attitudes in International Comparison: An Analysis of the ISSP Surveys 1993 and 2000.' Social Science Quarterly 84: 297-308.

Gardner, Gerald T. and Paul C. Stern. 2002. Environmental Problems and Human Behavior. 2nd ed. Boston, MA: Pearson Custom Publishing.

García Mira, Ricardo, Eulogio Real Deus, Maria Durán Rodríguez and José Romay Martínez. 2003. 'Predicting Environmental Attitudes and Behaviour.' Pp. 302-311 
in People, Places and Sustainability, edited by G. Moser. Seattle, WA: Hogrefe \& Huber Publishers.

Gärling, Tommy, Satoshi Fujii, Anita Gärling and Cecilia Jakobsson. 2003. ‘Moderating Effects of Social Value Orientation on Determinants of Proenvironmental Behaviour Intention.' Journal of Environmental Psychology 23: 1-9.

Grønhøj, Alice and John Thøgersen. 2009. 'Like Father, Like Son. Intergenerational Transmission of Values, Attitudes and Behaviours in the Environmental Domain.' Journal of Environmental Psychology 29: 414-421.

Gulyas, Emese, Andrea Farsang and Katalin Ujhelyi. 2007. A fenntartható fogyasztás kihívásai és lehetőségei Magyarországon: közlekedés, élelmiszerfogyasztás, háztartás. (Opportunities and Challenges of Sustainable Consumption in Hungary: Mobility, Food Consumption and Housing) Proceedings of the 'Sustainable Consumption Conference 2007' at Corvinus University, 18 December, Budapest, Hungary.

Intergovernmental Panel on Climate Change (IPCC). 2007. Climate Change 2007: The Physical Science Basis. Summary for Policy Makers. Geneva: IPCC.

Kalof, Linda, Thomas Dietz, Paul C. Stern and Gregory A. Guagnano. 1999. 'Social Psychological and Structural Influences on Vegetarian Beliefs.' Rural Sociology 64: 500-511.

Karp, David G. 1996. 'Values and Their Effect on Pro-Environmental Behavior.' Environment and Behavior 28 (1): 111-133.

Leopold, Aldo. 1949. A Sand County Almanac. New York: Oxford University Press.

Naess, Arne. 1989. Ecology, Community, and Lifestyle. Cambridge: Cambridge University Press.

Nickerson, Raymond S. 2003. Psychology and Environmental Change. London: Lawrence Erlbaum Associates.

Nilsson, Andreas, Chris von Borgstede and Anders Biel. 2004. 'Willingness to Accept Climate Change Policy Measures: The Effect of Values and Norms.' Journal of Environmental Psychology 24: 267-277.

Nordlund, Anika M. and Jörgen Garvill. 2002. ‘Value Structures Behind ProEnvironmental Behavior.' Environment and Behavior 34: 740-756.

Nordlund, Anika M. and Jörgen Garvill. 2003. 'Effects of Values, Problem Awareness, and Personal Norms on Willingness to Reduce Personal Car Use.' Journal of Environmental Psychology 23: 339-347.

Nunnally, Jum C. 1978. Psychometric Theory. 2nd ed. New York: McGraw-Hill.

Reid, Leslie. 1962. 'The Sociology of Nature.' Pp. 57-67 in Classics in Environmental Studies: An Overview of Classic Texts in Environmental Studies, edited by Nicolaas Johannes Maria Nelisson, Jan van Der Straaten and Leon Klinkers. Utrecht: International Books.

Rokeach, Milton. 1973. The Nature of Human Values. New York: The Free Press.

Schultz, P. Wesley. 2001. 'The Structure of Environmental Concern: Concern for Self, Other People, and the Biosphere.' Journal of Environmental Psychology 21: 327-339.

Schultz, P. Wesley, Vladiney V. Gouveia, Linda D. Cameron, Geetika Tankha, Peter Schmuck and Marek Franěk. 2005. 'Values and Their Relationship to Environmental Concern and Conservation Behavior.' Journal of Cross-Cultural Psychology 36: 457-475.

Schultz, P. Wesley and Lynette Zelezny. 1999. 'Values as Predictors of Environmental Attitudes: Evidence for Consistency across 14 Countries.' Journal of Environmental Psychology 19: 255-265.

Schwartz, Shalom H. 1977. 'Normative Influences on Altruism.' Advances in Experimental Social Psychology 10: 221-279.

Schwartz, Shalom H. 1992. 'Universals in the Content and Structure of Values: Theoretical Advances and Empirical Tests in 20 Countries.' Pp. 1-65 in Advances 
in Experimental Social Psychology, edited by M. Zanna. Orlando, FL: Academic Press.

Schwartz, Shalom H. 1994. 'Are There Universal Aspects in the Structure and Contents of Human Values?' Journal of Social Issues 50: 19-45.

Schwartz, Shalom H. 2008. 'Cultural Value Orientations: Nature and Implications of National Differences.' Moscow: Moscow State University-Higher School of Economics Press. Retrieved 2 February 2012 (http://seangallaghersite.com/yahoo_site_admin/ assets/docs/Monograph_Cultural_Value_Orientations1.29340248.pdf).

Schwartz, Shalom H. and Anat Bardi. 2001. 'Value Hierarchies across Cultures. Taking a Similarities Perspective.' Journal of Cross-Cultural Psychology 32: 268-290.

Schwartz, Shalom H., Gila Melech, Arielle Lehman, Steven Burgess, Mari Harris and Vicki Owens. 2001. 'Extending the Cross-Cultural Validity of the Theory of Basic Human Values with a Different Method of Measurement.' Journal of Cross-Cultural Psychology 32: 519-542.

Seligman, Clive and Albert N. Katz. 1996. 'The Dynamics of Value Systems.' Pp. 53-75 in The Psychology of Values: The Ontario Symposium Vol. 8. Hillsdale, NJ: Lawrence Erlbaum Associates.

Singer, Peter. 1975. Animal Liberation: A New Ethics for Our Treatment of Animals. New York: New York Review and Random House.

Steg, Linda and Judith I. M. de Groot. 2010. 'Explaining Prosocial Intentions: Testing Causal Relationships in the Norm Activation Model.' British Journal of Social Psychology 49: 725-743.

Steg, Linda, Judith I. M. de Groot, Lieke Dreijerink, Wokje Abrahamse and Frams Siero. 2011. 'General Antecedents of Environmental Behavior: Relationships Between Values, Worldviews, Environmental Concern, and Environmental Behavior.' Society and Natural Resources 24 (4): 349-367.

Steg, Linda, Lieke Dreijerink and Wokje Abrahamse. 2005. 'Factors Influencing the Acceptability of Energy Policies: Testing VBN Theory.' Journal of Environmental Psychology 25: 415-425.

Stern, Paul C. 2000. 'Toward a Coherent Theory of Environmentally Significant Behavior.' Journal of Social Issues 56 (3): 407-424.

Stern, Paul C., Thomas Dietz and Linda Kalof. 1993. 'Value Orientations, Gender, and Environmental Concern.' Environment and Behavior 25: 322-348.

Stern, Paul C. and Thomas Dietz. 1994. 'The Value Basis of Environmental Concern.' Journal of Social Issues 50 (3): 65-84.

Stern, Paul C., Thomas Dietz and Gregory A. Guagnano. 1998. 'A Brief Inventory of Values.' Educational and Psychological Measurement 58 (6): 984-1001.

Thøgersen, John and Folke Ölander. 2002. 'Human Values and the Emergence of a Sustainable Consumption Pattern: A Panel Study.' Journal of Economic Psychology 23: 605-630.

Thøgersen, John and Folke Ölander. 2006. 'To What Degree Are Environmentally Beneficial Choices Reflective of a General Conservation Stance?' Environment and Behavior 38: 550-569.

Verplanken, Bas and Rob W. Holland. 2002. 'Motivated Decision Making: Effects of Activation and Self-Centrality of Values on Choices and Behaviour.' Journal of Personality and Social Psychology 82: 434-447. 